\title{
1
}

\section{Institutional Transformation and Change: Insights for Faculty Developers}

\author{
Peter D. Eckel \\ American Council on Education
}

This chapter presents a series of insights about the process of institutional change and how leaders might implement it. Since the majority of energy goes into what the institution should do, little attention in higher education is given to how institutions should go about change. Based upon six years of work with 24 diverse institutions working on a range of change agendas in two projects, this chapter presents some conceptualizations of change and offers some language to discuss the type of intended change that might be useful for faculty developers and other campus leaders. It identifies three key elements in the change process and offers insight on strategies to implement them. It then connects these elements to the important role of faculty developers.

\section{INTRODUCTION}

Those individuals involved with faculty development and bringing about change and improvement on their campuses are well versed in the reasons for higher education to do things differently, adopt new pedagogies, create new relationships with students and other stakeholders, and think more critically about better serving the public good. They are familiar with the external pressures and the new opportunities that are creating new environments within which higher education must work. Thus, we can quickly move beyond the discussion of key challenges and emerging opportunities. 
In many instances, campus leaders know what to do; they have identified the needed changes that will help the institution improve in key ways. This chapter presents a series of insights about the process of institutional change and how leaders might implement it. Since the majority of energy goes into what the institution should do, little attention in higher education is given to how institutions should go about change. Based upon six years of work with 24 diverse institutions working on a range of change agendas in two projects, this chapter presents some conceptualizations of change and offers some language to discuss the type of intended change that might be useful for faculty developers and other campus leaders. It identifies three key elements in the change process and offers insight on strategies to implement them. It then connects these elements to the important role of faculty developers.

\section{ACE Projects on Transformation}

To assist institutions of higher education as they responded to their changing environments, the American Council on Education (ACE) launched the Project on Leadership and Institutional Transformation in 1995 with 26 public and private institutions, including community colleges, liberal arts colleges, comprehensive and doctoral universities, and research universities. Two institutions elected not to continue in the project's final two-year phase. (Appendix 1.1 lists the 26 participating institutions and their change agendas.)

The participating institutions joined the project with a range of change agendas. Some were shifting to a student- or learning-centered culture from a faculty-centered one, or infusing technology across the institution to improve teaching and learning. Others were rethinking faculty responsibilities and roles, implementing new ways of making decisions, or recrafting the curriculum and its purposes. Over time, the institutions' agendas evolved-some became more complex and challenging, as one change led to another, and others grew more limited in scope and less profound in their potential effects. The path of change took twists and turns, sped up and slowed down, and the substance of the change agendas took on new dimensions over time. The process was never linear; unexpected events and unintended consequences of predictable occurrences shaped the course of change in every institution.

The goals of the project were to assist institutions on their journeys of change to help them achieve their goals. We sought to help campus change leaders (faculty and administrators with the responsibility for 
leading institution-wide change) articulate a comprehensive agenda for change. We provided on-campus support through visits by experienced consultants and sponsored meetings of campus teams to share their successes and challenges and to collectively explore issues of institutional change. The project was organized to give institutions a supportive structure and language to think more deeply and intentionally about the complexities and challenges of change. We sought help their institutions develop the capacity for intentional change through reflection and learning. From their experiences we drew a series of insights and now seek to disseminate the learning to administrative and faculty leaders and policy makers.

We further refined our ideas through the Kellogg Forum on Higher Education (KFHET), a partnership to explore and better understand institutional change and transformation involving campus leaders from Alverno College, the Minnesota State College and University System, Olivet College, Portland State University, and the University of Arizona; faculty from The Center for the Study of Higher and Postsecondary Education at the University of Michigan, The Higher Education Research Institute at the University of California-Los Angeles, and The New England Resource Center for Higher Education at the University of Massachusetts-Boston; and staff from the W. K. Kellogg Foundation and ACE.

This partnership sought to combine experiences of leading transformational change with a variety of research and case studies highlighting the process of institutional change and transformation. Through presentations, wide-ranging discussions, papers, and campus visits, the KFHET partners of campus leaders, scholars, and association and foundation staff explored and exchanged ideas about change in higher education. Through this continued refinement, the ideas presented here were tested and refined.

\section{Typology of Change}

One of the first insights from the project was the difficulty of talking about change and transformation. We discovered that the terms "change" and "transformation" were problematic in several ways. The terms frequently provoked emotional responses among faculty, staff, and students, leading many institutional leaders to avoid them altogether. Campus leaders were concerned that the terms would elicit resistance and defensiveness, and instead chose the concepts of improvement and enhancement. While some people on campus were excited and energized 
by the idea of change and transformation, others found it threatening. The notions of change, and particularly, transformation, on many campuses were seen to devalue an institution's and individual's accomplishments and commitments.

Participants also defined the terms differently. In some instances, change meant doing anything differently, no matter how large or small. At other institutions, change was altering a discrete set of activities or creating new structures, and at others, change was about connecting to largescale modifications and launching new endeavors. The term transformation was also broadly and inconsistently defined. Some institutions used the term loosely, meaning a variety of interrelated changes that added up to something more than adjustments or innovations. Other times, transformation was implied to mean a complete break with the past. These people inferred transformation to be a fundamental shift in institutional identities and purposes, disregarding history and mission to start anew.

Developing a set of common definitions within the project was an important basis for clear communication and common understandings. Differentiating among types of change helped institutional leaders better describe the degree of change they sought, and helped create more intentional and reflective change processes. Institutional leaders could develop change processes consistent with the type and magnitude of the desired change.

Two basic descriptors-depth and pervasiveness-can describe categories of change. Figure 1.1 outlines four types of institutional changeadjustment, isolated change, far-reaching change, and transformational change.

FIGURE 1.1

Typology of Change

\begin{tabular}{|c|c|c|c|}
\hline & & & pth \\
\hline & & Low & Higb \\
\hline & Low & $\begin{array}{l}\text { Adjustments } \\
\text { (I) }\end{array}$ & $\begin{array}{l}\text { Isolated Change } \\
\text { (II) }\end{array}$ \\
\hline & $H i g b$ & $\begin{array}{c}\text { Far-Reaching } \\
\text { Change } \\
\text { (III) }\end{array}$ & $\begin{array}{c}\text { Transformational } \\
\text { Change } \\
\text { (IV) }\end{array}$ \\
\hline
\end{tabular}


The first quadrant is adjustment-a change or a series of changes that are modifications to a practice. Changes of this nature are revisions, alterations, or renewals. They occur when current designs or procedures are improved or extended. An adjustment may improve a process or the quality of a service, or it might be something new. Nevertheless, it is not a drastic alteration and does not have deep or far-reaching effects.

The second quadrant, isolated change, is deep but limited to one unit or a particular area; it is not pervasive. Depth focuses on how profoundly a change affects behavior or alters structures. Deep change implies a shift in values and assumptions that underlie the usual way of doing business. It requires people to act and think differently. The deeper a change, the more it is infused into the daily lives of those affected by it. An example of an isolated change is an academic department that decides service is of central importance. In this unit, hiring, promotion, and tenure decisions are heavily based upon faculty service records, students engage in service-learning as a integral part of their course work, the curriculum is rethought around community-based learning, and faculty members are annually recognized for service contributions beyond the campus.

The third quadrant is far-reaching change; it is pervasive but does not affect the organization very deeply. Pervasiveness refers to the extent to which a change is extensive across the institution. The more pervasive a change, the more it crosses unit boundaries and touches different parts of the institution. The use of computers is a familiar example of pervasive change. Computers sit on most faculty members' desks, students have access to computer labs, and many have their own computers. Furthermore, computers are used in university offices across campus for everything from tracking student accounts and inventory in the bookstore to submitting grades and analyzing data for research. However, the effect is limited and does not go deeply into the institution.

The final quadrant is transformational change. Transformation occurs when a change is both deep and pervasive. It is deep, addressing those assumptions about what the institution does, how it behaves, and what produces. In other words, transformation goes to the core of the institution. It is pervasive, a collective, institution-wide phenomenon. It is cultural change, altering the beliefs, values, norms, underlying assumptions, structures, processes, and policies. Transformation does not entail fixing discrete problems or adjusting and refining current activities. Our definition of transformation does not imply that institutions will change completely. Institutions in the projects sought to retain the 
basic functions of teaching, research, and service, but aimed to alter the ways in which they performed them and rethink the operating principles behind them.

Absent from our definition of transformation is the concept of speed. Because transformation is deep and pervasive, and it alters culture, most American institutions would not show dramatic and far-reaching results quickly. Transformation is most likely to occur through evolutionary rather than revolutionary steps. Specific contexts and internal factors influence the rate of change differently for institutions. Most colleges and universities do not have the cultures, the structures, or sufficient environmental pressures to bring about rapid transformation. We observed that transformation is a five-, ten- (or more) year journey.

Although Figure 1.1 presents the four types of changes as distinct, on most campuses, change is a composite of these types. Rather than change being discrete, within one quadrant, its dimensions may be thought of as overlapping. A change may be more or less pervasive, or it may be more or less deep. As was often the case, the magnitude of the agenda changed over time. Some institutions started out seeking isolated change, but through a cascading effect, the change agenda touched other units. Other institutions began with large hopes of transformation, only to scale back their intended efforts.

\section{The Change Process: Three Straightfortward Tasks}

The second set of insights from the project focuses on the process of bringing about transformational change. Through six years worth of observations, visits, conversations, reports, and meetings through two projects, we have learned that transformational change is about three fundamental tasks: 1) creating institution-wide momentum and energy for change, 2) removing barriers to change and elements that reinforce the status quo, and 3) helping people to think differently and adopt new mental models. All of the institutions in the ACE projects that made significant progress on their change agendas were able to create processes and strategies to do these three things. However, these tasks are not easily accomplished. The challenge for campus leaders is to determine strategies that will work within their individual contexts and cultures to accomplish these tasks.

These insights reflect the strategies and approaches used by the institutions that made the most progress on their institutional transformation agendas in the two projects. We came to call them "transforming" insti- 
tutions, because by their own admission, the work of transformational change is never complete. Successes led to new challenges, calling for more change.

\section{Create Institution-Wide Momentum and Energy}

Because of higher education's decentralized nature, competing priorities and objectives, norms of autonomy, and individual faculty academic freedom, any change effort requires a tremendous amount of momentum and energy to reach all areas of the institution. Institutions can also too easily rest on past successes without critical self-examination and become complacent. The following strategies were used by institutions that made the most progress on their change agendas to generate the needed institution-wide momentum and energy for change.

Actively made a compelling rationale for cbange. Transforming institutions had leaders who framed the change agenda in ways that were constructive to their efforts. Leaders articulated in clear and compelling ways why the institution had to undertake the proposed change. These leaders realized that key constituents must recognize the necessity for action before they willingly participate. That need for action must speak personally to faculty, administrators, staff, and other campus stakeholders. Leaders connected the need for change with important institutional and individual values: improving student learning, increasing excellence, and becoming more socially responsible. They positioned the change agenda as essential to a better future, not simply a different one. Leaders used a variety of approaches to make the case compelling. Some successful campuses used a data-driven approach, collecting hard data and conducting studies to assess the extent of the challenges. Other institutions took a softer approach, using qualitative factors-stories, beliefs, anecdotes, assumptions, and aspirations-to make the case for change.

Framing the change agenda constructively also involved explicit dissemination strategies, what one faculty leader called "an internal PR campaign.” Regular presentations of data, highly visible ad hoc task forces, widely disseminated reports, periodic columns in campus newspapers, and special newsletters helped convey why the change is important. Leaders also engaged in informal conversations, using unstructured time at the beginning and end of meetings to bring others into the discussion of why the change was needed to improve the institution.

Identified tbe right timing. Institutions that progressed had leaders who identified the right issues to tackle at the right time in the institution's life. Timing the introduction of the change agenda was important. 
For some institutions, the right timing meant not introducing new challenges immediately on the heels of resolving a difficult set of issues or soon after a divisive decision. For others, new challenges provided a catalytic event that infused new energy and enthusiasm after getting through a difficult period. In other instances, leaders built on the positive energy and confidence of a job well done. In each case, the right time meant something different depending upon the institution's historic trajectory.

The timing also had to be right in the rhythms of academic life. Institutions that made progress neither introduced new, complex issues at peak times in the semester, such as when faculty were busy starting their classes, nor did they make decisions over the summer that would affect faculty. Rather, change leaders chose to introduce ideas and start work when they could capture the most attention and time. They also worked to moderate the pace of change. Institutional leaders learned that too much change at once could easily overwhelm the campus.

Created ricb opportunities for involvement. The leaders at transforming institutions created a variety of opportunities for people to participate in meaningful ways. These opportunities allowed faculty and staff to choose the timing of their involvement, the length of their commitments, the degree of intensity, and the specific projects. Participation was flexible and people were able to change the ways they participated over the course of time. People could be highly involved at the beginning, take time away, and rejoin in a different capacity. Because opportunities varied, they capitalized on the various strengths of participants. Institutional transformation requires many talented hands, and although passionate leaders are important, they cannot effect transformation by themselves.

Identified cbampions. Recognizing that change would not occur simply by the effort of a dedicated few, leaders at transforming institutions identified and tapped champions across campus. Because of the depth and pervasiveness of transformational change, people in different units played important roles in leading the change efforts across the institution. Department chairs, senior faculty, and midlevel administrators were essential to make the changes last. Campus change leaders made sure to give the champions the support, assurance, and resources needed to bring about changes in their areas.

Used public deadlines effectively. Campus leaders used public deadlines to keep the change process moving. Sometimes these deadlines were determined by external groups, such as due dates for funding pro- 
posals. At other times, internal events, such as board meetings, budget cycles, or the printing of the course catalog, created important deadlines. By making deadlines well known and the potential risks of missing them public, leaders were able to keep the process on track. At the same time, leaders neither created or enforced arbitrary deadlines for quick decisions, nor did they set unrealistic timelines that would lead to premature decisions that later might be overturned or need to be revisited.

Gained external recognition. Institutions successful with change gained energy and momentum through a variety of external relationships with other institutions, funding agencies and philanthropies, and other national projects. These off-campus supporters and collaborators enhanced legitimacy on campus, introduced new ideas and solutions, and helped institutions overcome an insularity that impeded progress. Frequently, they resulted in new resources, sometimes substantial, to contribute to the change efforts. Institutions gained recognition in prestigious journals, and from funders such as the Kellogg Foundation, National Science Foundation, and FIPSE. External recognition and being touted as a leader in higher education strongly benefited on-campus change efforts.

\section{Remove Barriers}

Effecting institutional change is as much about removing obstacles as it is about introducing new things. Institutions can easily become tied down and remain stuck in the status quo without recognizing that to do things differently institutions must remove barriers and elements that reinforce the status quo. To accomplish this task, project institution leaders used the following strategies.

Developed new skills and knowledge. Institutional leaders recognized the difficulty of implementing new changes without providing adequate training or faculty development. To do new things requires mastery of new knowledge and skills. Institutions that made progress toward transformation developed intensive and comprehensive development programs for staff, administrators, and faculty. For instance, one institution, to support its change agenda, offered a range of services and programs, including workshops for department chairs, a mentor program for junior faculty, a range of seminars on teaching, learning, assessment, and community-based learning, and workshops and brown bag lunches on the scholarship of teaching. It also runs an orientation for new faculty. Each activity was aligned with the direction and goals of the transformation agenda. 
Secured new resources. One of the most common barriers preventing change is inadequate resource. Institutions that made progress found new sources of revenue from private foundations, state legislatures, and increased endowment returns that they invested in change. For example, two institutions were able to secure one-time large investments from their states to launch important projects. This needed money went to purchasing computers and upgrading facilities that would support their changes in teaching and learning. Other times, new funds were created through internal reallocation processes or from savings in other areas. New funds, in addition to providing the resources to do new things, also created a sense of legitimacy for the changes. Faculty and staff saw these as investments as recognition of their good work.

Created new units and positions. Campus leaders recognized that their institutions needed to create new units and positions to support their change agendas. The current organizational chart was insufficient. They created units to provide new services, such as community-university relations and centers for teaching excellence or for computing, technology, and pedagogy. They also created new administrative positions that had key elements of the change agenda in their portfolios. These new positions were frequently filled by faculty leaders on short-term leaves or through course buy-outs. These new positions and offices meant someone was responsible for the issues surrounding the change and sent the message that these issues are important enough to receive staff, budgets, and office space.

Tapped shared governance bodies constructively. The forms and functions of institutional governance, such as faculty senates and joint faculty-administrative planning groups, vary across institutions. Institutions that made progress toward transformation developed processes to tap these decision-making bodies effectively and did not violate well ingrained procedures. They expected governance processes to be constructive and worked to ensure that they were, rather than approaching them as impediments to change. By working constructively with governance leaders and adhering to the expected roles for campus governance, institutional leaders were able to use governance as a facilitator of change. At the same time that these institutions honored the traditional means of decision-making, they were not afraid to create new, ad hoc bodies that met institutionally defined thresholds for legitimacy that could work faster and assemble the necessary leaders better than standing governance committees. They balanced formal governance and its structures 
and procedures with new, innovative, responsive task forces of faculty and administrators (and, frequently, students).

\section{Help People Think Differently}

Transformational change is not only about doing things differently, it is also about thinking differently, both institutionally and individually. Because it is cultural, transformational change forces people to ask what the changes mean for themselves, their activities, and their assumptions. We observed two ways that transforming institutions demonstrated new institutional thinking. In some instances, colleges and universities attached new meanings to familiar language and concepts. For example, one institution recognized that it had redefined what it means to be a good teacher in its new technology-rich environment. No longer was it someone with well-organized lecture notes ready to present information, but a good teacher now was someone who knew how to use the available technology to help students actively engage with the material. Other times, institutions developed new language to describe new activities and changed assumptions and priorities. For example, one institution collectively added the words "customer" and "client" to its collective vocabulary. Faculty and administrators decided that the institution's customers were the companies that hired their graduates, the local community where their graduates lived, and the state legislature that provides the institution with resources. They thought that their students were more accurately described as clients. This new language helped articulate how they thought differently about the ways the institution served its different stakeholders. It helped the campus to differentiate the various ways it was responsible for learning, to whom, and in which ways.

At institutions that made progress on their transformation agendas, leaders created opportunities for people to come together to question the status quo, to explore the ways it had become insufficient, to question assumptions, to tell stories, and to posit new ideas. Institutions that made progress on their change agendas used some of the following strategies that help people to think differently and change their preconceived notions.

Created numerous campus conversations. Ongoing and widespread conversations to clarify and create new meaning rather than to advance or argue positions were major factors in helping individuals and institutions think differently about themselves. Such conversations allowed significant numbers of people to learn about problems and challenges from a broad, institutional perspective, creating a deeper understanding and 
greater investment in the entire institution. These opportunities allowed faculty and staff to wrestle collectively with ideas, to try out new priorities and ways of thinking, and to align key concepts with new realities. Then they could explore the ways in which they personally could adjust to the emerging future. Through these conversations, institutions developed new common language and a consensus on key ideas.

Benefited from outsiders and tbeir ideas. Institutions that made significant progress on their change agendas benefited from the ideas, comments, suggestions, and confrontations from interested outsiders who challenged key institutional beliefs and assumptions and introduced new ideas. Some institutions invited outside speakers to attend campus retreats or sponsored lecture series. For example, one institution working on diversity and social engagement created a lecture series of national and international speakers including church and civic leaders, social activists, writers, and government officials from the United States and abroad who addressed ideas of social responsibility and the civic role of the university. Some campuses sent groups of faculty and administrators to regional and national conferences. Other campuses sent teams to visit other institutions working on similar issues. Many change leaders widely distributed key readings and discussed them at retreats, during weekly or monthly meetings, or through reading groups specifically organized as professional seminars. In all cases, leaders went beyond simply distributing readings or disseminating ideas: They actively engaged the campus in discussions of ideas.

Created processes to articulate a set of guiding ideas. Change leaders organized processes to develop a set of concrete ideas that would shape the direction of the change agenda and connect it to important institutional values. These ideas typically manifested themselves in documents. Although the documents created often made lasting contributions, the process of creating, drafting, circulating, discussing, rewriting, presenting, and polishing the document helped people to think differently. The process of writing down important ideas got people to talk about their assumptions, engaged them intellectually, and got them to think deeply about difficult issues. These documents became campus compacts, statements, and discussion papers that later shaped institutional direction and, in some cases, informed strategic plans.

Used cross-departmental work groups. Many of the institutions created cross-departmental work teams that helped foster new ways of thinking. These work groups brought together faculty and staff from across the institution who had different perspectives and different assumptions. The 
tasks they were charged with, their interactions, and their collective explorations led to discussions about beliefs, assumptions, and ideas. The cross-fertilization of ideas helped people see different perspectives, challenge beliefs, and adopt new perspectives.

Gave public presentations. Institutions created numerous opportunities for people to present publicly their ideas and talk about their institution's change agenda. The practicality of putting together and delivering presentations helped unfreeze mental frameworks. Organizing and putting together a presentation for public consumption demanded people to articulate their ideas and assumptions, sometimes helping to highlight inconsistencies. Speaking aloud created another opportunity for individuals or groups of people to catalyze their thoughts. Finally, presentations created an opportunity for feedback and questioning. The cumulative effect of preparing and the act of speaking and responding to questions helped people adopt new ideas and perspectives.

\section{Conclusion: Implications for FACULTY DEVElopers}

The insights presented here have direct implications for those involved in faculty development. The chapter began describing a typology of change, with an emphasis on the depth and pervasiveness of a change agenda. The deeper and more pervasive the change, the more it has the potential to be transformational. We learned through our observations that an explicit recognition of how much change is desired is essential to crafting effective change strategies. Without articulating the intended scope and magnitude of the intended change, leaders can identify strategies that leave their efforts far short of intended goals. An important role for faculty developers is to help the institution think about how much change is needed (adjustments, far-reaching change, isolated change, or transformation) and develop appropriate strategies to effect that level and breadth of change. Faculty developers have an important institutionwide perspective to understand the complexity of problems, opportunities, and constraints. They are uniquely positioned to be a conduit between faculty and administrators and have contact with a range of faculty from different departments and disciplines. The nature of their work, and their place within the institution, provide ample opportunities to lead and shape the campus discussion about how much change is needed.

Beyond this role, faculty developers can play active roles in leading change. This chapter suggests three central elements important to effecting transformational change-creating momentum and energy, removing 
barriers, and getting people to think differently. Within each of these three areas, faculty developers can make vital contributions.

Faculty developers are in central roles to help craft and disseminate a compelling rationale for change. They are often bridges to the external environment and links between departments, and, at universities, across colleges. Because of their contact with faculty in a variety of units, they can help campus leaders better understand the rhythms of campus life. They have a good sense of when timing is wrong to introduce a change agenda, and when faculty are preoccupied with classes, grading, advising, and other important deadlines. They know the highs and lows of campus life and the academic calendar. They have insights about when the institution might best be ready to accept a new large-scale undertaking. Faculty developers, most likely, also know the informal, yet influential, faculty leaders. They can play important roles in identifying champions who will strengthen an institutional change effort. They also know the points of potential resistance and understand how to work around naysayers. Finally, to create momentum and energy needed for change, faculty developers can play important roles in gaining external recognition for campus efforts. They can help secure external grants to support change activities and gain external recognition for campus efforts.

Faculty developers can help remove barriers that reinforce the status quo and prevent the institution from making important improvements. Because of their primary responsibilities, they can help faculty and staff develop new skills and knowledge. By aligning development opportunities with the needs of the change agenda, they can facilitate change. Many of the institutions in the two projects developed extensive faculty and staff development programs specifically to advance the transformation agenda.

Finally, faculty developers can help people think differently. They can create opportunities for facilitated, institution-wide conversations about key elements of change and what it means for faculty and staff. Through formal workshops and symposiums and informal brown bag lunches, faculty developers can clarify ideas and get people to become aware of and reconsider their preconceived notions. Faculty developers can bring in outsider speakers who help the institution thoughtfully explore different ideas and assumptions. Through speaker series and guest lectures and organized campus reading groups, faculty developers can introduce new ideas and develop methods to debate and explore the applicability of ideas to the institution and its future direction. Developers can encourage and facilitate public presentations related to the institutional 
change agenda. Through the activities sponsored and hosted by faculty developers, opportunities arise for faculty and staff to create and deliver public presentations, both on campus and off, that help to clarify their own thinking and challenge preconceived notions by those attending.

\section{NoTE}

Portions of this chapter appear in the On Change occasional paper series, produced as part of the American Council on Education (ACE) Project on Leadership and Institutional Transformation. The author acknowledges the ideas and contributions of Madeleine Green and Barbara Hill, coauthors of those papers. The occasional papers are available in PDF files or for purchase from the bookstore of the ACE web site: http:// www.acenet.edu.

\section{Contact:}

Peter Eckel

Assistant Director, Kellogg Projects on Institutional Transformation American Council on Education One Dupont Circle, NW (Suite 800)

Washington, DC 20036

(202) $939-9444$

(202) 785-8056 (Fax)

Email: Peter_Eckel@ace.nche.edu

Peter Eckel is assistant director of the Kellogg Projects on Institutional Transformation at the American Council on Education. This work was completed as part of the Kellogg Forum on Higher Education, a partnership to explore and better understand institutional change and transformation involving ACE, the W. K. Kellogg Foundation, Alverno College, The Center for the Study of Higher and Postsecondary Education at the University of Michigan, The Higher Education Research Institute at the University of California-Los Angeles, Minnesota State College and University System, The New England Resource Center for Higher Education at the University of Massachusetts-Boston, Olivet College, Portland State University, and the University of Arizona. 


\section{ApPendix 1.1 \\ ACE Project on Leadership and Institutional Transformation Participating Institutions and Their Change Initiatives}

\section{Ball State University}

Redefining relationships with the larger community

\section{Bowie State University}

Shared governance, outcomes assessment, and merit-based performance pay

\section{California State Polytechnic University, Pomona}

Developing and implementing an integrated strategy for enhancing learning and teaching with technology

\section{Centenary College of Louisiana}

Strengthening the academic community without sacrificing academic freedom

\section{The City College of the City University of New York}

Maximizing student success

\section{College of DuPage}

A transformative planning process

\section{El Paso Community College District}

The pathway to the future/El Paso Al Futuro

\section{Kent State University}

Moving the strategic plan forward: Cross-unit planning and implementing

\section{Knox College}

Faculty life in a changing environment: Family, profession, students, and institutional values

\section{Maricopa County Community College District}

Learning@Maricopa.edu

\section{Michigan State University}

Enhancing the intensity of the academic environment

\section{Mills College}

Reexamine and revitalize the interrelationship between undergraduate women's education and specialized graduate programs for women and men 


\section{Northeastern University}

Call to action on cooperative education

\section{Olivet College}

Creating a culture of individual and social responsibility

Portland State University

Developing faculty for the urban university of the 21 st century

Seton Hall University

Transforming the learning environment

State University of New York College at Geneseo

Review, debate, and revision of general education requirements

\section{Stephen F. Austin University}

Revitalizing faculty, administration, and staff

University of Arizona

Building academic community: Department heads as catalysts

\section{University of Hartford*}

Planning and managing technology

\section{University of Massachusetts-Boston}

Assessing student outcomes

\section{University of Minnesota}

Improving the collegiate experience for first-year students

University of Puerto Rico, Rio Piedras

Reconceptualizing the baccalaureate degree

\section{University of Wisconsin-La Crosse*}

Building community: An institutional approach to academic excellence

\section{Valencia Community College}

Becoming a learning-centered college: Improving learning by collaborating to transform core college processes

\section{Wellesley College}

Improving the intellectual life of the college

$\left({ }^{*}\right.$ Participated in years $\left.1-3\right)$ 